\title{
O PENSAMENTO EDUCACIONAL DE INTELECTUAIS CURITIBANOS NA REVISTA “A ESCOLA” (1906)
}

\author{
Nilvan Laurindo Sousa \\ Universidade Estadual de Ponta Grossa - UEPG
}

\section{RESUMO}

O presente artigo objetiva apresentar o pensamento educacional de intelectuais curitibanos na revista "A Escola". Esta revista apresentou-se ideologicamente como uma possibilidade de investigação de uma realidade aparente na busca da totalidade dos seus fatores determinantes ao contexto em que estava imersa, bem como dos seus agentes e do projeto educacional que estes defendiam. A intelectualide dos representantes da imprensa curitibana residiu essencialmente na realização de um projeto político e educacional, onde a imprensa desempenhou funções de dominação cultural, a qual procurou atingir grupos sociais emergentes, forjados com crescimento das forças produtivas e das relações sociais capitalistas. Nestes grupos de intelectuais ligados às burguesias urbanas ascendentes encontravam-se políticos, jornalistas, técnicos, professores e outros.

Palavras-chave: Imprensa; Intelectuais curitibanos; Educação.

\section{EDUCATIONAL THOUGHTS OF CURITIBANOS INTELLECTUALS IN "A ESCOLA" MAGAZINE, 1906.}

\begin{abstract}
This paper aims at presenting the educational thoughts of curitibanos intellectuals in the magazine "A Escola "(The School). This magazine presented ideologically, as a possibility for investigation of an apparent reality in search of all the determinants to the context in which it was immersed, as well as their agents and the educational project they envisioned. The intelligentsia of the representatives of the curitibana press resided primarily in achieving a political and educational project, where the press acted as the cultural domination tool, which tried to reach emerging social groups forged with the growth of productive forces and capitalist social relations. These groups of intellectuals, linked to the rising urban bourgeoisie, were politicians, journalists, technicians, teachers and others.
\end{abstract}

Keywords : Press; Curitibanos intellectuals; Education.

Alguns intelectuais ${ }^{1}$ da elite curitibana integrantes do Clube Curitibano, fizeram parte da revista denominada "A Escola", juntamente com o Grêmio de Professores Públicos do Estado do Paraná, periódico produzido em 1906 até 1910, o qual tinha como editor chefe Sebastião Paraná ${ }^{2}$ e, posteriormente, Dario Vellozo ${ }^{3}$, este via na educação como o principal caminho para "transformar" a sociedade ao desenvolvimento e ao progresso. Sua vida desde cedo esteve relacionada ao mundo da imprensa e da literatura, trabalhou no jornal mais antigo do Paraná, o Dezenove de Dezembro. Vellozo defendeu a República e o lugar do Estado no cenário nacional. 
A revista " $A$ Escola”, periódico do grêmio de professores público do Paraná, editada em Curitiba no período de 1906 a 1910, com duração de quatro anos. Sob a direção de Sebastião Paraná de fevereiro a julho de 1906, quando assume então Dario Vellozo até dezembro de 1910 (MARACH, 2007).

Em 1906, data de criação da revista "A Escola", a cidade apresentava um certo progresso, há uma efervescência econômica, elementos que entrevê aspectos do perfil intelectual da cidade em função do momento econômico fomentado pelo ciclo da ervamate.

A revista A Escola contou com um diversificado número de colaboradores, alguns se sobressaiam em função do número de matérias apresentadas, são eles: Dario Vellozo, Emiliano Perneta, Azevedo Macedo, Bandeira, Nestor Castro, Leôncio Correia, Rocha Pombo, Nestor Vitor, Antonio Braga, Generoso Borges, Domingos Nascimento, Cônego Braga, Serafim França, Ricardo de Lemos, Ermelino de Leão, Alluizio França, Júlio Perneta, Claudino dos Santos, Carvalho Mendonça, Chichorro Junior, Romário Martins e Lucio Pereira (MARACH, 2007).

O periódico "A Escola" atendia aos interesses do Estado para intervir no processo educativo da escola pública, ela se apresentava como um mecanismo capaz de realizar "promoção" social, um meio de reprodução de uma ideologia visando uma conformação social a serviço de uma elite letrada que mascarou as suas reais intenções, as contradições presentes na sociedade.

Na capa de edição da revista "A Escola” já encontramos pistas da veiculação da presente revista com o Estado, uma vez que seus agentes estavam diretamente atrelados a revista, constou em seção permanente os nomes dos membros da Instrução do Paraná: Diretor Geral Arthur Pedreira de Cerqueira; Inspetor da Capital, Sebastião Paraná; Secretário José Conrado de Souza, como diretor do Grêmio Presidente Francisco Guimarães, primeiro Secretário Veríssimo de Sousa e segundo Lourenço de Souza e Tesoureiro Brasílio da Costa (SOUSA, 2013).

Esta revista apresentou-se ideologicamente como uma possibilidade de investigação de uma realidade aparente na busca da totalidade dos fatores determinantes ao contexto em que estava imersa, bem como os seus agentes, o projeto educacional que estes defendiam. O periódico "A Escola", por meio de seu grupo de editores, via na educação a possibilidade de "civilizar" os cidadãos da República conduzindo-os ao "progresso" da nação. Para este grupo, a escola tinha o papel fundamental de preparar intelectual e moralmente os alunos para que estes assumissem e desempenhassem seu papel na sociedade.

É a escola primária uma instituição supernamente civilizadora. Officina do Espírito infantil, é nesse recinto bemdicto que a intelligencia dos pequenos seres, ainda não desabrochada para o conhecimento, se vae desenvoluindo e inundando da luz cambiante e redemptora da instruçção (ESCOLA, 1906, p 2).

A ideologia preponderante no discursos dos intelectuais curitibanos a escola era vista como um espaço de disciplinamento da força de trabalho, um dos locais legítimos. A alfabetização não passava de um fetichismo em seu lugar mesmo o que era imperativo para a educação republicana, era formar o indivíduo para as novas demandas da sociedade. Na República três temas emergiram: A construção do Estado Nacional, a formação do trabalhador para o capital e a transformação do súdito em cidadão (NORONHA, 2009). 
O discurso ideológico dos republicanos era para que se incutisse no povo o sentimento nacionalista, pela educação se pretendia formar o trabalhador. A preocupação com a educação estava pautada em fatores econômicos, uma vez que a indústria no Brasil teve relevância no final do século XIX, evidencia-se neste período em que o capitalista se instalava de forma gradativa.

O pensamento republicano estava arraigado nos princípios liberais e no cientificismo, os intelectuais estavam imersos na ideologia do "progresso" e na missão "redentora" da educação, sendo ela um eficiente instrumento para a edificação da república e da democracia, bem como o disciplinamento e a ordem. A elite pensante inspirada nos moldes europeus pedia a "[...] disseminação das escolas, da instrução: o pão da instrução pública parece-me que é aquele que o Estado deve distribuir com mais generosidade" (PEREIRA, 1997, p.5)

A República buscou uma identificação com a educação, tendo esta a missão da divulgação de um ideal cívico e o moralismo patriótico e, ainda, uma conformação ideológica. Houve uma preocupação direcionada a divulgação do nacionalismo e do patriotismo visando assim a popularização da educação a qual seria sua base. Para tanto, era preciso a consolidação de mitos e festividades cívicas para promover a admiração pelos grandes vultos e heróis do passado que deveriam ser exemplos e inspiração para as novas gerações. Era preciso enfatizar as glórias nacionais, os feitos heróicos e os personagens ilustres, os quais seriam matéria-prima nas salas de aulas (TRINDADE, 1996).

A educação teve neste contexto caráter moralizante e cívico, os quais foram amplamente propagados pela escola de diversas formas, com a utilização de símbolos patrióticos, festividades, calendário cívico dentre outros.

A imprensa se apresentava como um instrumento ideológico a serviço da ordem social vigente e da manutenção das desigualdades, naturalizando-as. Sendo assim, foi de fundamental importância a compreensão deste processo uma vez que pode-se encontrar pistas para o desvendamento e a compreensão da realidade de um dado momento, sendo ela capaz de consolidar práticas sociais, métodos educacionais, de convalidar condutas, legitimar práticas, definir modelos, divulgar anseios, visando com isto um controle da sociedade para melhor atender os interesses do capitalismo que se instaura (SOUSA, 2013).

As informações veiculadas na imprensa fornecem subsídios para compreender o contexto, o cenário, os personagens, os interesses e as práticas sociais conduzindo a uma interpretação da realidade evidenciadas mediante as contradições presentes na sociedade uma vez que ela apresenta o aparente, invisibilizando as reais condições da maioria da população marginalizada que vivia nos arredores das cidades.

Uma das práticas realizadas na imprensa paranaense foi de classificação quanto ao mérito de alunos, evidenciando assim o êxito destes, os bem sucedidos, os méritos, uma forma de forjar modelos a serem seguidos.

A cada final de ano letivo, durante todo o período da Primeira República brasileira, os periódicos curitibanos noticiam os resultados dos exames finais dos cursos primários das escolas públicas e particulares. Nomes femininos constam freqüentemente dessas listagens que asseguraram seus "conscienciosos conhecimentos", asseverando estarem as educandas habilitadas à matrículas no Gymnasio Paranaense na Escola Normal (TRINDADE, 1996, p. 31). 
Apresenta-se aqui uma prática em que a sociedade adotou divulgar na imprensa resultados de exames finais, esta postura, de certa forma, acirrou a competitividade, a individualidade, características essenciais do liberalismo. Pode ser percebido, especialmente, se considerar o caráter de universalidade e sedução que são atribuídos ao princípio do individualismo uma vez que, desta forma, impulsionou o desejo do homem na direção da autonomia (SANTANA, 1996).

A educação e o projeto educacional republicano ${ }^{4}$ não foi deixado de lado, muito pelo contrário, a imprensa, por meio dos intelectuais, tomou cabo das discussões educacionais fundamentadas na ideologia liberal e nos princípios filosóficos do positivismo. A revista foi uma divulgadora de métodos e técnicas, modelos, práticas docentes, dentre outros. O periódico "A Escola" se propôs ser um mecanismo eficaz, visou a reprodução de uma ideologia vigente e a homogeneização da educação no Estado, apresentou-se, naquele contexto, como uma ferramenta de formação de professores uma vez que era insuficiente o número de professores formados, o que dificultava a implementação do projeto republicano para a educação no país.

\section{[...] falta de pessoal sufficientemente instruído e expressamente educado para o mister do professorado [...] Enquanto a Escola Normal não houver fornecido um grande contingente de competentes educadores, será impossivel uniformizar os méthodos de ensino, medida que carecemos adotar (A ESCOLA, 1908, p. 15)}

Com o advento da República, o contexto privilegia a circulação de ideias, há uma sensação de liberdade, ao menos para a elite. Esta sensação orientava a livre circulação de ideologias que impulsionaram a proliferação da circulação de inúmeros periódicos como revistas, jornais e boletins.

Para a ideologia do novo regime, a educação era o mais eficiente instrumento para a construção do Estado republicano "democrático", um regime político que se definia como sendo do "povo" e para o "povo", deste modo necessitava de uma "sólida" organização escolar capaz de oferecer uma formação política, mais completa possível, a "todos" os cidadãos. No discurso do novo regime, o "povo" passou a ter um "papel político" como "dirigente" do Estado, o qual tem como interesse e dever a difusão da educação popular (REIS FILHO, 1995).

Todavia a educação neste momento é vista como um serviço que exige grande dispêndio de recursos, sendo difícil a expansão da rede escolar com quantidade e qualidade de ensino para atender a crescente necessidade da população. As escolas particulares só podiam assumir quando contava com uma clientela economicamente capaz de "retribuir com taxas compensadoras", porém, a maioria da população era carente do ponto de vista educacional e também de recursos econômicos (REIS FILHO, 1995, p. 204).

Os intelectuais da imprensa curitibanos atribuíram ao Estado a função de criar e manter escolas nos diversos níveis, estas escolas teriam a função de preparar o futuro cidadão para que desempenhasse o papel político que o novo regime destinou aos brasileiros. O novo regime conferiu a tarefa primordial da escola a educação cívica, entendida como a compreensão fundamental dos cidadãos, deveria acontecer não apenas no plano de estudo da escola, mas também pelo "[...] rol de disciplinas como: História do Brasil, Geografia do Brasil, Economia Política, Educação cívica", que teriam o papel de ampliar o quadro de informações sócio-políticas indispensável ao exercício da cidadania (REIS FILHO, 1995, p.204). 
O sentido da ideologia dos grupos dominantes, dos quais se encontravam os membros da revista "A Escola" é a elaboração da "[...] falsa consciência que conduz à necessidade de esconder as verdadeiras relações de classe e, desta forma, garantir seus reais interesses, por meio de uma representação falsa e falseadora" de uma concepção particular do mundo que pretende revelar a todas as classes como uma verdade universal que surge como resposta às condições sociais concretas que se determinam, sendo a própria dinâmica da realidade que se localiza as condições que a determinam (CURY, 1978, p.6-7).

A elite pensante ${ }^{5}$ tinha a função de unificar os conceitos para criação de uma "nova cultura", que não se reduzia apenas a formação de uma vontade coletiva, capaz de adquirir o poder do Estado, mas a difusão de uma "nova" concepção de mundo e de comportamento. Torna-se fundamental o papel das instituições privadas da sociedade civil como a igreja, escolas, sindicatos, jornais, família e outros, como entidades consolidadoras de uma nova vontade e moral social.

\begin{abstract}
Além de procurar fixar seu modo de sociabilidade através de instituições determinadas, os homens produzem ideias ou representações pelas quais procuram explicar e compreender sua própria vida individual, social, suas relações com a natureza e com o sobrenatural. Essas ideias ou representações, no entanto, tenderão a esconder dos homens o modo real como suas relações sociais foram produzidas e a origem das formas sociais de exploração econômica e de dominação política. Esse ocultamento da realidade social chama-se ideologia (CHAUI, 1980, p. 8).
\end{abstract}

Uma destas instituições determinadas é a educação que torna-se protagonista do debate junto a imprensa periódica, por meio de uma elite letrada que tinha como objetivo de "conduzir" a população brasileira ao "progresso" e ao "desenvolvimento" moral, econômico e social. A escola tinha um papel fundamental neste momento do país, era urgente a necessidade de elevação do nível moral da nação que se encontrava mergulhada nas trevas, era preciso a emancipação do espírito cativo da ignorância (BASTOS, 1975).

Extraordinários são os serviços que presta a escola à civilização dos povos. Mais do que isso: a escola é o plintho inabalável e inevitável sobre que se alteia, majestoso e bello, o monumento altaneiro $e$ deslumbrantíssimo da civilização (ESCOLA, 1906, p.3).

O projeto pedagógico que visava "regenerar" o país estava baseado nos parâmetros do liberalismo. Setores liberais atuaram mediante a imprensa, educação e partidos, buscando, nesses campos, produzir novas elites dirigentes e formar a consciência nacional, uma tentativa de conquistar o "coração e a mente" da população (CARVALHO, 1990). A imprensa apresenta-se como agente da história capaz de manipular interesses, seus agentes são dotados de consciência que se determina na prática política (CAPELATO, 1989).

[...]outros igualmente aparelhados para os prelios gloriosos da inteligência [...] As pennas brilhantíssimas destes eximios litteratos e scienistas são sufficientes para impor e recommedar esta revista, que procurara cumbrir o ser dever em prol da expansão intellectual da terra paranaense (ESCOLA, 1906, p. 17). 
As primeiras décadas do século $\mathrm{XX}$, o centro urbano de Curitiba apresentava uma época de entusiasmo capitalista em Curitiba, um reflexo do que vive o país, ratificado pelas realidades urbanas visíveis, por meio do crescimento econômico, da industrialização e do grande fluxo de imigrantes. O discurso nas academias, institutos e centros de letras paranaenses contrastava com os problemas de desarmonização entre a cidade e o campo, o aumento demográfico nos centros urbanos decorrentes da imigração, bem como a consolidação do trabalho livre. Um processo denominado de modernização, ao menos para a burguesia nos centros urbanos, a imagem da cidade "moderna, limpa, ordenada e iluminada" fazia parte desse momento de repensar a sociedade pelas classes favorecida uma vez que a maioria da população encontrava-se nas imediações desprovidas de toda a sorte (MARACH, 2007, 15).

\section{Urbanização de Curitiba, primeira década do século XX}

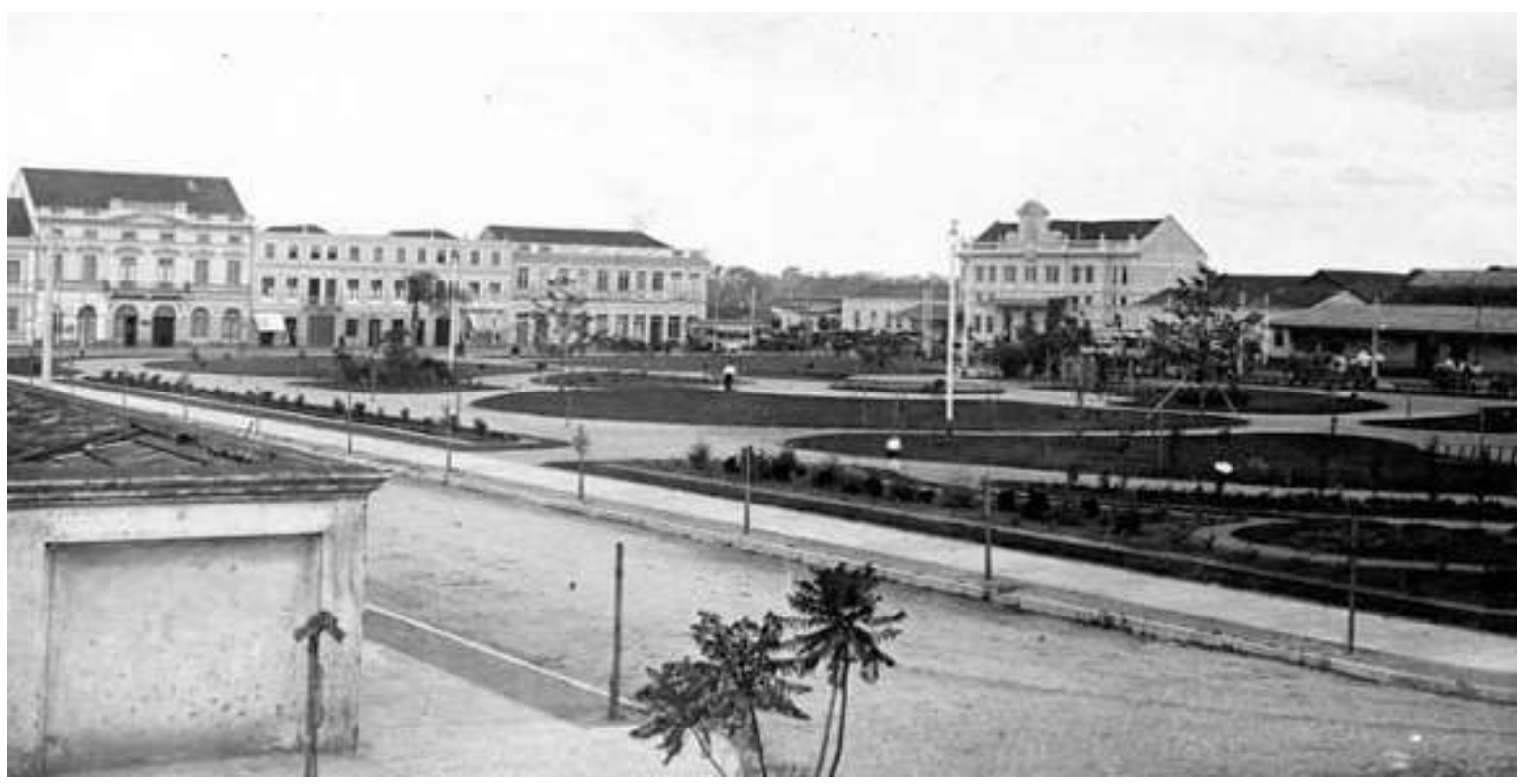

Fonte: Acervo da Fundação Cultural de Curitiba

Os escritores da Revista "A Escola" tinham a crença no futuro, aspecto fundamental para compreensão do projeto que visava a longo prazo "reparar" o presente, sabendo que os frutos deste trabalho não seriam saboreados a curto prazo, mas seus efeitos se refletiriam ideologicamente na geração vindoura e na sociedade de um modo geral. Este pensamento impulsionou os intelectuais do periódico aqui apresentado, os quais objetivavam uma "interferência" social, por meio da educação. Desta forma, seria possível "civilizar" a nação em conformidade às necessidades do mundo moderno, o sistema capitalista exigiu uma capacidade "intelectual" crescente de "todos", incluindo assim o sistema escolar, as sociedades de agrárias passaram a industrial, era preciso instruir a população para atender esta nova demanda.

[...] é certo que com o desenvolvimento do maquinismo, a ciência e a técnica se incorporam à máquina, é certo também que o desenvolvimento desta introduz uma série de exigências de qualificação da força de trabalho que traz consigo a aparição, consolidação e auge do sistema escolar institucionalizado. Outra mais complexa: se é certo que com o desenvolvimento do maquinismo se incorporam à máquina todas aquelas habilidades, isso não faz mais 
que afetar a força de trabalho, e não a capacidade criadora do homem (MARX, ENGELS, 2011, p.12).

Os escritores de "A Escola", na condição de elite pensante, encabeçaram este projeto, de um periódico educacional, que visou moralizar a população, tornando-os não apenas autossuficientes, mas devia encaminhar a população para a "civilização", livrando-a da ignorância e "revelar" a concepção de mundo coerente com a lógica do mundo moderno.

[...] a boa escola compõe-se essencial e indispensavlemente de muito requisitos: deve ser moralmente attractiva, intellectualmente attractiva, e até materialmente attrativa; deve ensinar o mais possível, o melhor possivel, e no menos tempo possível; tem obrigação impeterivel de semear na infancia os sentimentos christãos que se appreendem na prática do amor mutuo, e não na lettra morta de phrases decoradas; incumbe-lhe ser immaculada até da mais tenue sombra de sevicias; tem de dar conta ao Creador e tambem à sociedade do como conciliou ou deixou de conciliar o tres elementos de cada um dos individuos que se lhe confiaram: o entendimento, o coração, o corpo (ESCOLA, 1906, p.3).

Era constante o debate, na primeira metade do século XX, na imprensa sobre os métodos mais adequados a serem utilizados para a implementação do projeto educacional. Todavia, esta preocupação não era visando a emancipação dos indivíduos, ou mesmo a libertação destes das condições opressoras, uma vez que para isto era fundamental a formação de uma consciência emancipadora (SOUSA, 2013).

Não se pode negar que a educação, a ciência e a extensão do conhecimento são fundamentais no processo de formação da consciência, desta forma somente pela razão se poderá conseguir esta emancipação (MARX; ENGELS, 2004). Entretanto, o projeto da revista "A Escola" não se direcionava a este propósito emancipador, coube a educação neste projeto republicano o papel de naturalizar as desigualdades e a manutenção delas.

A escola burguesa é um molde que prepara para a fábrica e os escritórios, um instituto de treino para a prisão assalariada: A criança esta limitada a um único trabalho que é estudar, empalidecer com os rudimentos da gramática de manhã e de tarde, durante 10 e 11 meses por ano. [...]A escola coloca a teoria antes da prática (MARX; ENGELS, 1978, p. 37).

O ensino esteve em pauta como um dos pontos mais frequentes durante o século XX. Vários seguimentos da sociedade como personalidades políticas, artistas e até mesmo militares debatiam sobre esta questão. Os intelectuais a frente da revista " $A$ Escola" acreditavam que a educação seria a grande solução para os diversos problemas da vida moderna, tornar-se-ia viável o controle da população, a qual não poderia ser banida, já que o desenvolvimento do país dependia da sua força de trabalho.

O sistema de ensino é entendido, assim, como uma concreta qualificação da força de trabalho que alcançará seu aproveitamento máximo se conseguir também o ajuste e a integração dos indivíduos no sistema, única maneira de não desperdiçar sua força de trabalho, 
mas sim, aproveitá-la. Dito de outra forma: reproduz o sistema dominante, tanto a nível ideológico quanto técnico e produtivo (MARX;ENGELS, 2011, p15).

Os Colabores da Revista "A Escola" tinham como ideal a civilização da população, o que significava "[...] atribuir-lhe distinções e mantê-la sob controle" (MARACH, 2007, p.46). Caberia à educação o papel de "moldar o indivíduo, como vaso de barro". Este ideal não era apenas do grupo da revista, era uma crença que inspirava sobretudo a base ideológica da República (MARACH, 2007).

Este periódico do início do Século XX se propôs a ser um ponto de orientação dos professores, uma espécie de bússola para educadores, apresentava propostas, currículos, sugeria métodos e legitimava práticas docentes, apontava modelos de condutas a serem seguidos.

É forçoso que mestre, o educador da infância não descumpra os seus deveres, mas os exercite sem vacillações nem esmorecimento e dynamistisado por energias masculinas, afervorado do mais intenso desejo de bemfazer, propellido pelos dictames de uma consciência perseverantemente ajustada à rectilinea do bem. (ESCOLA, 1906, p. $3)$.

A revista periódica "A Escola" teve um papel fundamental quando se propôs ser uma formadora de opinião para o quadro de professores do Estado do Paraná, mas também no processo de personificar referências de práticas educativas, modelos a serem seguidos, métodos e materiais didáticos a serem utilizados.

O grupo de editores da revista "A Escola" preconizava um novo conceito de educação, o qual objetivava encaminhar o indivíduo para as profissões mais condizentes com a sociedade em desenvolvimento, com isso, passaram a divulgar a formação técnica, publicaram currículos dos cursos de forma apologética a formação profissionalizante, tais como Escola do Comércio, Escola Normal, Escolas Agrícolas.

A revista escola, por meio de seu grupo de intelectuais, orientava no sentido de que precisaria ser revista a forma como pais e alunos das camadas menos prestigiadas economicamente viam a escola, era preciso uma reformulação neste sentido. Agora se discutia uma educação para a classe trabalhadora, para os menos abastados economicamente. Os membros da revista em questão pretendiam fazer com que este segmento da sociedade marginalizado não enxergasse a escola como mero degrau rumo à ascensão social, mas núcleo cívico em que seria ensinado o necessário para fazer do indivíduo um cidadão defensor da nação e da própria subsistência (MARACH, 2007).

A pátria não é ninguém: são todos, e cada qual tem no seio della o mesmo direito a ideia, a palavra, a associação. A pátria não é um systema, nem uma forma de governo, é o ceo, o sol, o povo, a tradição, a consciência, o lar o berço, os filhos e o múmulo dos antepassados, a communhão da lei, da língua e da liberdade [...] Estamos a trabalhar esforçadamente pela instrução da infância e pelo levantamento moral da classe dos seus educadores é nosso desejo cordial cumprirmos a nossa missão com o maior devotamento e solicitude, certos como estamos de que assim prestaremos serviços de real valia ao progredimento e prosperidade do nosso querido Estado do Paraná (A ESCOLA, 1906, p. 60). 
O povo foi convocado para contribuir e solidificar o novo regime e a educação faria a instrução necessária e o levantamento moral dos cidadãos, era constante o discurso entusiasta pela educação que sintetizava expectativas de controle e modernização social. O nacionalismo se apresentava como a forma eficaz de valorização da pátria, desta forma "forjou-se um projeto político autoritário: educar era demoldagem de um povo "[...] conforme os anseios de Ordem e Progresso de um grupo que se auto-investia como elite com autoridade para promovê-los" (CARVALHO, 1989: p. 9).

O grupo a frente da revista "A Escola" desejava acordar a juventude pobre das escolas para a importância de outras profissões, as quais acreditavam que se tornariam gradativamente mais importantes diante dos novos tempos, não para os alunos, mas para a nova ordem vigente, ou seja, formação da força de trabalho. A elite intelectualizada integrante da revista "A Escola" defendia então uma educação voltada para o mercado de trabalho, orientava no sentido de uma formação aligeirada, uma vez que se tratava de formar os pobres para o mercado de trabalho, desta forma naturalizando as desigualdades e a manutenção da hegemonia da burguesia.

Muitas vezes poderia ser um industrial progressista, um commerciante emprehendedor, se faz um doutor que, em $75 \%$ dos casos, não se destacará uma pollegada da linha das mediocridades diplomadas (ESCOLA, 1906, p. 135).

A revista orientava a formação da agricultura e outras atividades ligadas ao setor primário, atividades consideradas como único meio de garantia do alimento necessário para abastecer a população. Defendia também, profissões que considerava fundamentais para a demanda daquele momento, as quais estavam relacionadas "[...] ao comercio, a indústria, à agricultura e a pecuária” (MARACH, 2007, p.58). Contrapondo assim, as profissões liberais pertencentes à burguesia como medicina, direito, engenharia.

Os intelectuais da revista "A Escola" objetivaram dar subsídios pedagógicos aos professores, evidenciaram a função da escola, a postura do professor frente aos alunos, métodos e condutas a serem adotados, visando assim conduzir o povo, por meio da educação, cada indivíduo no papel em que se acreditava, estaria de acordo com as habilidades naturais destes, que certamente não condizia com a educação tida pelo grupo de intelectuais da mencionada revista. Desta forma, visou-se satisfazer os anseios do governo, que pretendia ideologicamente "instruir" o povo.

Motivados ideologicamente pelo espírito da civilização e da modernidade ${ }^{6}$, a elite letrada curitibana se evidenciava pelo desejo de secularização da sociedade. Desta forma, há uma ênfase no discurso pela valorização do povo, bem como pelo o espírito científico, a laicização do Estado e a concepção evolutiva da sociedade.

\section{Conclusão}

Os republicanos utilizaram-se da educação e fizeram-na alicerce para a divulgação de seus ideais, evidencia-se o discurso em favor da modernização do Brasil. A lógica de progresso para eles estava baseada na divisão social do trabalho que era incompatível com os índices elevado de analfabetismo. Na República, a instrução pública passou a ser resolução para os problemas do novo regime. A educação era a responsável pelo engrandecimento do Estado. 
Os Intelectuais falavam em nome do povo, mas não pelo povo. Eles detinham o controle da imprensa que se expandia neste período e reproduziam um discurso oficial inspirado no positivismo e na Revolução Francesa com o jargão de liberdade, igualdade e fraternidade com ordem e progresso. O discurso republicano era em prol da democratização do ensino, indispensável para a formação do cidadão e 0 desenvolvimento do país.

A imprensa foi de forma gradativa se consolidando, as informações veiculadas nela, possibilitaram visualizar as relações de produção que constituíram a estrutura econômica da sociedade e as formas determinadas de consciência. Sendo ela artefato importante uma vez que por meio dela se tentou criar e se consolidar o imaginário social.

As contradições existentes, naquele contexto, são evidenciadas articulando-as aos processos que permearam a evolução das forças produtivas na sociedade capitalista que conduziu a organização da classe dominante, tanto no plano social como no plano político.

A intelectualide dos representantes da imprensa curitibana reside essencialmente na realização de um projeto político e educacional, onde a imprensa desempenhará funções de dominação cultural, a qual procura atingir grupos sociais emergentes, forjados com crescimento das forças produtivas e das relações sociais capitalistas. Estes grupos de intelectuais ligados às burguesias urbanas ascendentes encontram-se políticos, jornalistas, técnicos, professores e outros..

Por meio da imprensa se propagou os ideais republicanos para além da elite, eram necessárias outras abordagens, o que resultou a necessidade de manipular o imaginário e a construção de símbolos, alegorias e mitos na tentativa de utilizá-los como elementos legitimadores de ideais.

Para a concretização deste processo, a imprensa foi fundamental na disseminação e consolidação de um modelo de conduta, métodos a serem utilizados, com o objetivo de homogeneizar a educação coerente com o projeto republicano. A imprensa se apresentou como o principal meio de divulgação e disseminação de ideias, palco privilegiado de disputas, de interesses políticos, de legitimidade intelectual. Os periódicos se notabilizaram como um veículos de uma elite letrada para a elite letrada. A imprensa se apresentou como um instrumento ideológico a serviço da ordem social vigente e da manutenção das desigualdades, naturalizando-as.

A revista periódica "A Escola" teve um papel fundamental quando se propôs ser uma formadora de opinião para o quadro de professores do Estado, mais também, no processo de personificar referências de práticas educativas, modelos a serem seguidos, métodos e materiais didáticos a serem utilizados.

\section{Referências}

ARAUJO, Silvete Aparecida Crippa. Professora Júlia Wanderley, uma Mulher-Mito (1874 - 1918). Dissertação de Mestrado da Universidade Federal do Paraná, Curitiba, 2010.

BASTOS, Tavares. A província: estudo sobre a descentralização do Brasil. São Paulo. Ed. Nacional, 1975.

BASBAUM, Leôncio. História sincera da República:de 1889 a 1930, 2. ed. São Paulo: Edições L. B., 1968. 
CAPELATO, Maria Helena. Os arautos do liberalismo: imprensa paulista 1920-1945. São Paulo: Brasiliense, 1989.

CHAUI, Marilena. O que é ideologia. São Paulo: Brasiliense, 1980

CARVAlHO, José Murilo. Formação das Almas: o imaginário da República no Brasil. São Paulo: Companhia das Letras, 1990.

CARVALHO, M. M. C. A escola e a República. São Paulo: Brasiliense, 1989. (Coleção Tudo é História).

CAVAZOTTI, Maria Auxiliadora. O projeto republicano de educação nacional na versão de José Veríssimo. São Paulo: Annablume, 2003.

GRAMSCI, A. Cadernos do cárcere. Civilização Brasileira, v. 2. 2001.

CURY, Carlos Roberto Jamil. Ideologia e educação brasileira. São Paulo: Cortez \& Moraes, 1978

GONÇALVES JUNIOR , Ernando Brito. A educação pelo livro: uma análise do compêndio de pedagogia de Dario Vellozo (1907) - Dossiê História e Educação - Volume 7, número 10, dezembro de 2010.

MARACH, Carolina Baron. Inquietações Modernas: Discurso Educacional e Civilizacional no Periódico A Escola (1906 a 1910). Dissertação de Mestrado Universidade Federal do Paraná. Curitiba, 2007.

MARX, Karl; O capital: crítica da economia política. Livro 1, Volume 1. São Paulo, DIFEL, 1982.

MARX, Karl; ENGELS, Friedrich. Crítica da educação e do ensino. Tradução do Francês. RABAÇA, Ana Maria.Primeira edição. Lisboa. Moraes Editores, 1978.

Manuscritos econômicos e filosóficos e outros textos escolhidos. $2^{\mathrm{a}}$ ed. São Paulo: Abril Cultural, 2002.

. A ideologia Alemã V.1. São Paulo, Martins Fontes, 1984.

A ideologia Alemã V.1. São Paulo, Boitempo, 2011.

Karl Marx e Friedrich Engels. Textos sobre Educação e Ensino. Campinas, SP: Navegando, 2011

NORONHA, O. M. Educação e trabalho no contexto histórico da formação da Primeira República. LOMBARDI, J. C.; SAVIANI, D. (Orgs.), 2009.

PEREIRA, Luís Fernando Lopes. Paranismo: o Paraná inventado. Cultura e imaginário no Paraná da Primeira República. Curitiba: Aos Quatro Ventos, 1997.

REIS FILHO, Casemiro dos. A educação e a ilusão liberal: origens do ensino público paulista. Campinas, SP: Autores Associados, 1995

SANTANA, Luis Carlos. Liberalismo, ensino e privatização: um estudo a partir dos clássicos da economia política. Campinas, SP: [s.n].1996

SOUSA, Nilvan Laurindo. O PROJETO REPUBLICANO PARA A EDUCAÇÃO NO PARANÁ E O PROCESSO DE (DÊS) MISTIFICAÇÃO DE JÚLIA WANDERLEY, Dissertação de Mestrado Universidade Estadual de Ponta Grossa Curitiba, 2013. 
TRINDADE, Etelvina Maria de Castro. Etelvina Maria de Castro. Clotildes e Marias: Mulheres Curitibana na Primeira República. Curitiba: Farol do Saber, 1996.

\section{Fonte Primária}

A Escola, Curitiba, 1906 e 1908.

Notas

${ }^{1} \mathrm{O}$ modo de ser do novo intelectual não pode mais consistir na eloquência, motor exterior e momentâneo dos afetos e das paixões, mas numa inserção ativa na vida prática, como construtor, organizador, "persuasor permanente", já que não apenas orador puro - mas superior ao espírito matemático abstrato; da tecnica-trabalho, chega à técnica-ciência e à concepção humanista histórica, sem a qual permanece “especialista" e não se torna "dirigente" 1(especialista-politico). (GRAMCI, 2001, p. 53).

${ }^{2}$ Sebastião Paraná foi docente e diretor do Ginásio Paranaense, Superintendente Geral do Ensino, escritor e político (Deputado Estadual) influente no Estado: editor da revista A Escola e fundador do Jornal a Tribuna. (ARAUJO, 2010, p. 48-9).

${ }^{3}$ Dario Persiano de Castro Vellozo nasceu no Rio de Janeiro, em 26 de novembro de 1869, e mudou-se para Curitiba no ano de 1885, com 16 anos, na companhia do pai e do irmão. Vellozo foi poeta, tipógrafo e professor de História, fundou e teve participação na criação de várias revistas e jornais, foi um dos participantes da fundação do IHGPR(Instituto Histórico e Geográfico Paranaense) e criou o INPInstituto Neo-Pitagórico (GONÇALVES JR, 2010).

${ }^{4}$ A educação é um processo social de formação de gerações, subsidiada em fundamentos práticos-teóricos de uma dada sociedade, com conteúdos determinados pela produção de suas relações sociais e se expressam num projeto político. Nesse sentido, um projeto de educação para o país pode assumir diferentes conteúdos e objetivos em virtude do movimento histórico. (CAVAZOTTI, 2003, p.68).

5 Para BASBAUM, 1968, a Elite letrada, diz respeito aos profissionais liberais, "constituída de advogados, médicos, engenheiros, professores, jornalistas" que formavam uma categoria social que deu conteúdo ideológico à propaganda republicana. Já na primeira década da República, com a queda do florianismo, já se encontravam completamente desiludida do seus sonhos de liberdade, igualdade e fraternidade. O regime que se apresentava não era aquela República sonhada (BASBAUM, 1968, p.172).

${ }^{6}$ A modernidade para Marx é resultado de um longo processo de construção material, pautada nas ideias e valores abstratos como individualismo e liberdade de acordo com as interpretações liberais. É a decomposição da estrutura feudal impulsionada na expropriação dos meios de trabalho, visando assim a acumulação do capital e, com isto, revolucionar as estruturas de organização das relações sociais. Marx ao se referir a modernidade fez alusão mais do que o marco histórico arraigado em torno das idéias e valores abstratos disciplinada, racional e prospectiva a uma gama de transformações revolucionárias nas relações econômicas, políticas da sociedade as quais possibilitaram a confirmação do modo de produção capitalista (MARX, 1982).

Recebido em agosto-2013

Aprovado em setembro-2013 